\title{
Građa
}

\author{
Petar Macut \\ (Institut društvenih znanosti Ivo Pilar, Područni centar Vukovar)
}

\section{ZAPISNICI SA SJEDNICA TABORA USTAŠKE MLADEŽI VUKOVAR \\ (srpanj 1942. - travanj 1943.)}

UDK 06:94(497.5 Vukovar)“1942/1943“(093)

Stručni rad

Primljeno: 22. 9. 2017.

\begin{abstract}
Autor donosi zapisnike sa sjednica tabora Ustaške mladeži u Vukovaru od srpnja 1942. do travnja 1943. godine. U zapisnicima se nalaze podatci o djelovanju lokalne organizacije Ustaške mladeži u Vukovaru u razdoblju nešto kraćem od godine dana iz kojih se može dobiti dojam o intenzitetu, kvaliteti, preferencijama i načinu na koji je tabor, kao osnovna teritorijalna ustrojbena jedinica organizacije Ustaške mladeži, administrirao i vodio mušku i žensku mladež grada Vukovara od 7 do 18 godina. Zapisniku prethodi kraće objašnjenje ustroja i djelovanja Ustaške mladeži, te su dodatnim bilješkama uz tekst objašnjeni neki važniji momenti i informacije koje ovi dokumenti sadrže.
\end{abstract}

Ključne riječi: Nezavisna Država Hrvatska, Vukovar, Ustaška mladež, tabor

Ustaška mladež kao ustrojbena jedinica Ustaškog pokreta tek u posljednje vrijeme dobiva zasluženu pažnju. U hrvatskoj i europskoj historiografiji do sada je objavljena jedna monografija i tek nekoliko radova o toj temi. ${ }^{1}$ Bez

${ }^{1}$ Hrvatski povjesničar Franko Mirošević objavio je 2012. godine rad Ustaška mladež u Dubrovniku 1941. godine u svjetlu službenoga glasila "Hrvatski narod"“, Radovi Zavoda za povijesne znanosti HAZU u Zadru 54 (2012), str. 305-322, a Petar Macut rad Julije Makanec kao duhovni odgojitelj Ustaške mladeži, u: Intelektualci i rat 1939.-1947., zbornik radova s Desničinih susreta 2012., dio I., ur. Drago Roksandić, Ivana Cvijović Javorina (Zagreb, 
obzira na relativnu neistraženost navedene teme, jasno je da je ustaška organizacija koja je nastojala okupiti, organizirati i u ustaškom duhu odgajati sveukupnu hrvatsku mladež značajan i važan fenomen iz kojega se mogu iščitati važne činjenice o djelovanju Ustaškoga pokreta u cjelini.

Zapisnici koje ovdje predstavljamo pokrivaju područje grada Vukovara. Sedmom točkom Zakonske odredbe o osnivanju Ustaške mladeži određeno je da se na područjima župa, gradova i sela osnivaju stožeri, logori i tabori Ustaške mladeži, na čijem su čelu stožernici, logornici i tabornici. ${ }^{2}$ Osim teritorijalnog ustroja, koji je u početku pratio administrativni ustroj države, istom zakonskom odredbom određeni su i dužnosnici koji će taj ustroj voditi.

Mladež je podijeljena na mušku i žensku, a dobni okvir obuhvaćao je Ustašku uzdanicu (od 7-11 godina), Ustaške junake (od 11-15 godina) i Ustašku Starčevićevu mladež (od 15-18 godina). Na čelu tih dobnih skupina stoje zapovjednici, kao i na čelu pojedinih grana djelovanja na kojima su posebni odjelni upravitelji, i to za: vojničku prednaobrazbu, duhovni odgoj, promičbu, tjelovježbu, umijeće, zdravstvo, društveno-gospodarsku brigu te za kućanstvo (samo za žensku mladež).

Grad Vukovar je u smislu organizacije Ustaškoga pokreta pokrivao područje jednoga tabora. Stoga su svi imenovani dužnosnici na njegovom području taborski dužnosnici. Ustaška mladež na području jednoga tabora trebala je imenovati sljedeće dužnosnike: tabornika, zapovjednike Ustaške uzdanice, Ustaškoga junaka i Ustaške Starčevićeve mladeži, odjelne upravitelje za: vojnu prednaobrazbu, duhovni odgoj, promidžbu, društvovno-gospodarsku brigu, umijeće, zdravstvo, tjelovježbu i kućanstvo (samo za žensku mladež), te naposljetku zapovjednika radne službe. ${ }^{3}$ Uvidom u zapisnike tabora Ustaške

2013), str. 147-161. Goran Miljan početkom 2016. godine doktorirao je na temi Ustaške mladeži, obranivši disertaciju pod naslovom Young, Militarized, and Radical: The Ustasha Youth Organization, Ideology, and Practice, 1941-1945 (Central European University, Budimpešta). Kao posebne radove objavio je dva poglavlja iz disertacije, i to: Fašizam, sport i mladež ideja i uloga tjelesnoga odgoja i sporta u odgoju i organizaciji Ustaške mladeži, 1941.-1945., Radovi Zavoda za hrvatsku povijest Filozofskoga fakulteta Sveučilišta u Zagrebu 46 (2014), br. 1, str. 361-382; „Karizmatični“ Poglavnik? Poglavnik i formiranje karizmatske zajednice - primjena i korisnost Weberova koncepta karizme, Historijski zbornik 66 (2015), br. 1, str. 121-147. Kao četvrto poglavlje u knjizi objavljen mu je rad The Brotherhood of Youth - A Case Study of the Ustaša and Hlinka Youth Connections and Exchanges, u: Fascism without Borders. Transnational Connections and Cooperation between Movements and Regimes in Europe from 1918 to 1945, ed. Arnd Bauerkämper, Grzegorz Rossoliński-Liebe (New YorkOxford, 2017). U svibnju 2018. godine objavio je monografiju Croatia and the Rise of Fascism: The Youth Movement and the Ustasha During WWII. U drugoj polovici 2018. godine objavljena je i monografija o Ustaškoj mladeži na hrvatskom jeziku: Petar Macut, Ustaška mladež. Povijest organizacije koja je brinula o podmlatku Ustaškoga pokreta (Zagreb, 2018).

${ }^{2}$ Zakonska odredba o osnivanju Ustaške mladeži, Ustaša, 11/1941., br. 4, 11.

${ }^{3}$ Usp. P. Macut, Ustaška mladež, 277-278. 
mladeži Vukovar vidimo da njihova organizacija nije bila u potpunosti pokrivena svim potrebnim dužnosnicima. Međutim, ovi zapisnici nisu jedini mogući izvor podataka o dužnosnicima tabora Ustaške mladeži Vukovar.

Postoji nekoliko izvora iz kojih se mogu crpsti podatci o dužnosnicima Ustaške mladeži. U Hrvatskom državnom arhivu čuvaju se dva popisa dužnosnika Ustaške mladeži, jedan kojim je obuhvaćena muška mladež i drugi s popisom dužnosnica ženske Ustaške mladeži. ${ }^{4}$ Ovaj popis nastao je negdje krajem 1944. i početkom 1945. godine. Popis je izradilo Upravno zapovjedništvo Ustaške mladeži. Osim toga popisa, službeni mjesečnik Ustaške mladeži Dužnostnik, koji je izlazio od ožujka 1942. do prosinca 1944. godine, na posljednjim stranicama gotovo svakoga broja donosio je imenovanja i razrješenja dužnosnika. Dodatni izvor podataka za početne mjesece ustroja Ustaške mladeži, od sredine srpnja 1941. pa do veljače 1942. godine, nalazi se u dnevnim novinama Hrvatski Narod. S pokretanjem Dužnosnika, Hrvatski Narod više ne donosi popise imenovanih dužnosnika. I lokalni tisak važno je vrelo, jer su mnogi prenijeli imenovanja svojih sugrađana na razna dužnosnička mjesta, bilo u Ustaškom pokretu, bilo u Ustaškoj mladeži. U slučaju tabora Ustaške mladeži Vukovar imamo dva takva lokalna izvora podataka: katolički tjednik Hrvatski borac iz Vukovara ${ }^{5}$ i Novo Borovo, tjednik koji je izdavala tvornica gume i obuće Bata-Borovo. ${ }^{6}$ Objedinjenom analizom svih ovih izvora možemo donekle rekonstruirati imena većine dužnosnika i dužnosnica Ustaške mladeži iz Vukovara.

Osim utvrđivanja identiteta dužnosnika Ustaške mladeži, ovi zapisnici sadrže i kratke opise raznih inicijativa i sazivanja sastanaka te donose brojne teme o kojima se raspravljalo na sjednicama: o organiziranju sastanaka sa dobnim skupinama mladeži, njihovom participiranju na raznim priredbama, raspodjeli zadataka i organiziranju raznih proslava. Iz zapisnika se može iščitati na koji su način lokalni dužnosnici Ustaške mladeži provodili direktive nadređenih zapovjedništava, posebno stožernoga zapovjedništva i Upravnog zapovjedništva iz Zagreba. Osim direktiva, prisutne su i lokalne inicijative kojima se pokušavalo pokazati rezultate rada s pripadnicima Ustaške mladeži iz Vukovara svih dobnih skupina.

Nekoliko je razloga zašto je potrebno objaviti dokumente koji slijede: oni su historiografski izvor te su sami po sebi vrijedni; zapisnici sa sjednica tabora Ustaške mladeži vrlo su rijetko sačuvani; arhivski izvori za upoznavanje organizacije Ustaške mladeži općenito su slabo sačuvani i vrlo siromašni;

\footnotetext{
${ }^{4}$ Hrvatska, Hrvatski državni arhiv, Zagreb, fond 1549, Zbirka zapisa upravnih $i$ vojnih vlasti Nezavisne Države Hrvatske (HR, HDA, f. 1549, ZIG NDH), kut. 196 i 197.

${ }^{5}$ Hrvatski borac iz Vukovara izlazio je od prosinca 1941. do lipnja 1942. godine. Više o tom tjedniku vidjeti u: Petar Macut, Vukovarski Hrvatski borac - katolički i ustaški tjednik, Scrinia Slavonica XVII (2017), br. 1, 253-290.

${ }^{6}$ Tjednik Novo Borovo izlazio je od srpnja 1941. do listopada 1944. godine.
} 
dokumenti su pisani rukom na stranicama obične bilježnice A4 formata, koja već sada pokazuje znakove propadanja od vlage, te su djelomično nečitljivi.

Nije jasno tko je vodio zapisnike, ali je nedvojbeno da su to činile različite osobe, budući da se nekoliko različitih rukopisa javlja tijekom toga razdoblja. Zapisnici su vođeni na ukupno 25 stranica bilježnice koje su istrgnute zajedno iz sredine te čine jedan samostalni arak. Ti su zapisnici dio vođenih zapisnika, jer je očito da su se sastanci održavali i prije i poslije razdoblja koje ovi dokumenti obuhvaćaju.

Datum održavanja prvog sastanka, 29. srpnja 1942., poklapa se gotovo s godišnjicom osnutka te omladinske organizacije Ustaškoga pokreta, koji je poglavnik Ante Pavelić 'zakonskom odredbom' osnovao 12. srpnja 1941. godine. Osim toga, 30. srpnja 1941. godine imenovani su prvi dužnosnici Ustaške mladeži za stožer velike župe Vuka. ${ }^{7}$

Zapisnici sa sjednica tabora Ustaške mladeži nalaze se u Hrvatskom državnom arhivu. ${ }^{8}$

Zapisnici sa sjednica Ustaške mladeži tabora Vukovar predstavljaju važan historiografski izvor pomoću kojega je moguće dobiti uvid u aktivnosti i način funkcioniranja lokalne organizacije Ustaške mladeži. Iako se ovdje radi o kratkom razdoblju od nekoliko mjeseci, iz njih je moguće rekonstruirati dinamiku provođenja direktiva, kako iz središnjice (Zapovjedničtva Ustaške mladeži Zagreb), tako i iz neposredno nadređenog Stožera Ustaške mladeži Vuka I.

Zapisnici nam neposredno predstavljaju opseg rada i probleme na koje je u svom radu nailazila lokalna organizacija Ustaške mladeži tabora Vukovar. Objavljivanjem ovakve vrste historiografskih izvora dobivamo mogućnost usporedbe između propagandnih uspjeha, o kojima možemo čitati u brojnom tisku organizacije Ustaške mladeži, i stvarnosti koja je pred lokalne dužnosnike Ustaške mladeži stavljala brojne prepreke.

Vjerujući da se zapisnici lokalnih organizacija Ustaške mladeži zasigurno nalaze i u drugim arhivima, ovo je ujedno poziv da se oni objave i tako stave na uvid zainteresiranoj znanstvenoj i stručnoj javnosti.

${ }^{7}$ Usp. Imenovanja u Stožeru Ustaške Mladeži Velike Župe Vuka, Novo Borovo, br. 3, 1. kolovoza 1941., 4.

${ }^{8}$ HDA, f. 1549, ZIG NDH, kut. 202, dok. br. 6-25. 


\section{Zapisnik sa sjednice održane dana 29. VII. 1942. god. \\ Sjednicu je otvorio brat Tabornik u $19^{\mathrm{h}}{ }^{\mathrm{g}}$}

Sa slijedećim redom:

I. Povećanje sastanaka dob. skup.

U.M. radi smotre.

II. Učenje vježbi:

Petak: Uzdanica

Ponedjeljak: Junak

Utorak: St. Ml.

$\mathrm{Na}$ sastancima se imaju raditi samo proste vježbe za župsku smotru.

Zapovjednici dobnih skupina dužni su naučiti vježbe i preneti ih na pripadnike.

\section{Prikupljanje podataka Ust. M1.}

Svi zapovjednici imaju prikupiti podatke po dobnim skupinama, do 1. VIII. 1942. god i predati ih taboru.

IV. Eventualije.

U subotu dne 1. VIII. 1942. naručiti ping-pong stol.

Plan rada za VIII. mjesec.

Sjednica završena u $20^{\mathrm{h}}$

Sjednici prisustvovali:

Tabornik v.d. Dragutin [potpis nečitljiv] ${ }^{10}$

Od. za društ. gos. brigu Josip Thel [potpis nečitljiv] ${ }^{11}$

${ }_{9}^{9}$ Pisano rukom, latinica.

${ }^{10}$ Prvi tabornik Ustaške mladeži u Vukovaru bio je Dragutin Kitić. Dužnost je vršio od 30. VII. 1941. do 23. II. 1942. (Imenovanja Upravnog zapovjedništva, Dužnosnik, 1942., br. 2, 110). V. d. tabornik vjerojatno je imenovan nakon veljače 1942. godine, a imao je isto ime kao i prethodnik, s tim da mu je prezime nečitljivo. Ta je osoba svoju privremenu dužnost vršila do početka 1943. godine, kada njegovu dužnost preuzima Mijo Kuhner (Gostovanje Ustaške mladeži u Iloku, Novo Borovo, br. 12, 26. III. 1943., 4). Nije poznato do kada je točno dužnost tabornika vršio Kuhner, ali postoji podatak iz Novog Borova koji predstavlja Vinka Žigrića tabornikom u Vukovaru (Sastanak učeničke mladeži Ustaškog junaka u Vukovaru, Novo Borovo, br. 20, 25. V. 1944., 3).

${ }^{11}$ Taborni odjelni upravitelj za društvovno-gospodarsku brigu u Vukovaru bio je Mijo Kuhner (Imenovanja u Stožeru Ustaške Mladeži Velike Župe Vuka, Novo Borovo, br. 3, 1. VIII. 
v. d. Zap. St. Ml. [potpis nečitljiv] ${ }^{12}$

Zap. Junaka Tomić Tomislav ${ }^{13}$

Zap. Uzdanice Pletikapić Mirko ${ }^{14}$

Zapisnik sa sjednice održane dana 6. VIII. 1942.

Sjednicu je otvorio brat zap. bojn. u $19.30^{\mathrm{h}}$

Ovim redom:

I. Rešavanje duga za binu: ${ }^{15}$

Ustaška m. kako žen. tako i m. daje iz svoje blagajne po $300 \mathrm{kn}$ (tri stotine kuna) za otplaćivanje građe.

II. Udio za opravku motornog vozila.

Iz blagajne M.U.M. se ima isplatiti za opravku motornog vozila koji je svojina Prip. bojne tri stotine kuna. Sa tim da se tim vozilom mogu koristiti U. Mladež.

III. Nabavka sprava.

Potrebno je što hitnije nabaviti zidne ljestvice, prijestol, konopac i karike

1941., 4). Budući da u srpnju na tom mjestu nalazimo Josipa Thela, jasno je da je nešto prije toga Kuhner smijenjen sa svoje dužnosti. Vjerojatno je bio raspoređen na neku drugu dužnost unutar organizacije Ustaške mladeži do siječnja 1943., kada preuzima mjesto tabornika. Nije mi poznato tko je preuzeo odjel za društvovno-gospodarsku brigu poslije.

${ }^{12}$ Prvi zapovjednik ustaške Starčevićeve mladeži bio je Krunoslav Metzinger (Imenovanja u Stožeru Ustaške Mladeži Velike Župe Vuka, Novo Borovo, br. 3, 1. VIII. 1941., 4). Dužnost je vršio negdje do srpnja 1942., kada ga je netko zamijenio. Nečitljivog v. d. zapovjednika Starčevićeve mladeži zamijenit će na sljedećem sastanku Miroslav Pletikapić.

${ }^{13} \mathrm{Na}$ toj dužnosti naslijedio je prvoimenovanoga taborskog zapovjednika Ustaškog Junaka Ivana Vidu. Nije poznato točno kada, ali svakako prije srpnja 1942. godine. Usp. Imenovanja u Stožeru Ustaške Mladeži Velike Župe Vuka, Novo Borovo, br. 3, 1. VIII. 1941., 4.

${ }^{14}$ Prvi imenovani dužnosnik na ovo mjesto je Stjepan Keglević. Istoimenog dužnosnika Ustaške mladeži nalazimo na poziciji zamjenika odjelnog upravitelja za umijeće u Zapovjedništvu Ustaške mladeži u Zagrebu od 2. X. 1941. Ako se radi o istoj osobi, pretpostavljam da je onda u listopadu 1941. godine na njegovo mjesto taborskog zapovjednika Ustaške uzdanice imenovan Mirko Pletikapić.

${ }^{15}$ Vjerojatno se radi o bini koja je sagrađena ili iznajmljena za smotru spomenutu u prethodnom zapisniku. 
IV. Slanje pripadnika na [nečitljivo] ${ }^{16}$

sa strunjačom, koje će biti smještene u prostorijama Pripr. bojne.

15. VIII. u Zemun se šalju slijedeći: St. m. Ivan Hakek, Tomić Tomislav (Jakob Đenđinović) Ust. Jun. Pletikosić Miroslav Zvonko Tomić (Sava Dragaš) sa sljedećim disciplinama U.M. skok u dalj, trčanje $100 \mathrm{~m}$, bacanje koplja i trčanje $1000 \mathrm{~m}$. Ust. Jun. skok u dalj, trčanje $60 \mathrm{~m}$.

V. Nabavka glasno govornika

U slučaju nedostatka novčanog spremni smo potpomoći nabavku glasno govornika koji je neophodno potreban.

Sjednica je završena u 20 časova.

Sjednici prisustvovali:

Za dom - spremni!

Zap. Prip. bojne: Andrej D[nečitljivo]

V. D. tabornica: Belan Katarina ${ }^{17}$

V. D. tabornik: [nečitljivo]

Rojn. Jun. Mohorovičić J. Ružica ${ }^{18}$

Zap. St. m. Pletikapić Miroslav ${ }^{19}$

Izv. za dr. g. br. Josip Mohorovičić20

${ }^{16}$ Iz sadržaja teksta koji slijedi očito se radi o putovanju na natjecanje u Zemun.

${ }^{17}$ Prva poznata tabornica ženske Ustaške mladeži Vukovar je Zdenka Pold. Dužnost je vršila od 23. V. 1942. do 22. X. 1943. (Dužnostnik, 1944., br. 1-3, str. 25). Da su ovi podatci nepouzdani govori nam i slučaj v. d. tabornice u Vukovaru koja je svoju dužnost vršila po ovom zapisniku i 6. VIII. 1942., dakle u razdoblju kada je tabornica trebala biti Zdenka Pold. Osim toga, kao što će se vidjeti iz zapisnika od 6. II. 1943., dužnost tabornice preuzet će Jela Šičara, koja se ne spominje niti u Dužnostniku, niti u Popisu dužnostnika. Nije poznato do kada je Šičara bila tabornica, ali je izvjesno da je tu dužnost vršila barem neko vrijeme. Stoga nije jasno kada je zapravo Zdenka Pold bila djelatna tabornica Ustaške mladeži Vukovar.

${ }^{18}$ Skraćenica Rojn. vjerojatno označava rojnicu. Roj je odjel koji ima 9-15 članova, a zapovijeda mu zapovjednik roja. Usp. Vježbovnik Ustaške mladeži (Zagreb, 1942), 17.

${ }^{19}$ Dužnost je preuzeo početkom kolovoza 1942. godine. Nije poznato do kada ju je vršio.

${ }^{20}$ Nečitljivog odjelnog upravitelja za društvovno-gospodarsku brigu iz prethodnog zapisnika naslijedio je taborski izvjestitelj za društvovno-gospodarsku brigu Josip Mohorovičić, što je zapravo identična dužnost, samo promijenjenog naziva. Nije poznato do kada je dužnost vršio. 
Zapisnik sa sjednice održane 2. IX. 1942. godine

Sjednicu je otvorio brat Tabornik u $19.00^{\mathrm{h}}$

sa slijedećim redom

I. čitanje zapisnika sa prošle sjednice:

Zapisnik je primljen.

II. Opomena zapovjednicima za mjesečni izvještaj

Da se do svakog trećeg izvještaji moraju poslati $\mathrm{u}$ logor. ${ }^{21}$

III. Blagajnički izvještaj

Izvještaj se prima. (Br. 3)

IV. Nogometna utakmica

Pošto nismo dovoljno spremni to još ne možemo ovu utakmicu primiti, ali kroz izvesno vrijeme ćemo je moći primiti.

V. Eventualije

Sjednica je završena u $20,10^{\text {h }}$

Prisustvovali su:

$[\ldots]^{22}$

$[\ldots]^{23}$

Tomić Tomislav

Pletikapić Miroslav

$[\ldots]^{24}$ Jakob

$[\ldots]^{25}$ Zvonimir

${ }^{21}$ Neredovito slanje mjesečnih izvještaja bila je opće raširena pojava među dužnosnicima Ustaške mladeži.

${ }^{22}$ Potpisan je nepoznati v. d. tabornik.

${ }^{23}$ Nečitko.

${ }^{24}$ Nečitko.

${ }^{25}$ Nedostaje dio stranice. 
Zapisnik sa sjednice održane 13. XII. 1942.

Sjednicu je otvorio tabornik u $16,5^{\text {h }}$

sa slijedećim redom.

1.) čitanje zapisnika sa prošlog sastanka

Zapisnik je primljen!

2.) Ispadi pripadnika:

Za svaki prestup se pripadnici kažnjavaju:

1. opomenom

2.) novčana kazna

3.) popravilište.

3.) da se kazne sledeći pripadnici:

Belaci Stjepan, drugu kaznu

Mikuleci Zvonimir

Faculjak Josip

4. Eventualije

Sastanak je završen u $17,30^{\mathrm{h}}$

Sastanku su prisustvovali:

$[\ldots]^{26}$

Zapisnik sa sjednice održane dne: 20. I. 1943.

Sjednicu je otvorio brat tabornik u $19^{\mathrm{h}}$

sa slijedećim redom.

I. Čitanje zapisnika sa prošlog sastanka

II. Sastanci za ovaj mjesec.

Zapisnik je primljen.

U pomanjkanju goriva u ovom mjesecu se neće održati više nijedan sastanak.

${ }^{26}$ Jedan nečitak potpis. 
III. Nabavka inventara.

IV. Tko će da ga nabavi?

Da se kod g. Johana Sehucidera kupi jedan orman, za taborsku arhivu.

Prima u dužnost Zap. St. ml. brat Pavao Višnjevski. ${ }^{27}$

V. Eventualije:

Sjednica je završena u 20,25

Za Poglavnika i Dom spremni!

Prisustvovali:

$[\ldots]^{28}$

Zapisnik sa sjednice održane dne 26. I. 1943.

Sjednicu je otvorio brat tabornik

u $18,15^{\text {h }}$ sa slijedećim redom

I. Čitanje zapisnika sa prošle sjednice.

II. Plan rada za slijedeći tjedan a(za Uzdanicu)

Zapisnik je primljen.

Održati prosvijetni sastanak dne 31. I. 1943. g. u sobi P.P. i to: Sastanak počinje u $9^{\text {h }}$. : Ispitivanje sa prošlog sastanka. Poglavnikova duša od 6-9 načela, ${ }^{29}$ čitanje. Novi zadatci: Koračnica, „Ustaška se vojska diže.“

b. za Junak.

Održati prosvijetni sastanak dne: 31 . I. 1943. u sobi P.P. i to: sastanak počinje u $10^{\mathrm{h}}$ : Iz duhovnog odgoja: 1.2.3. Ust.

\footnotetext{
${ }^{27}$ Pavao Višnjevski je posljednji od trojice poznatih taborskih zapovjednika Ustaške Starčevićeve mladeži. Dužnost je preuzeo krajem prosinca ili početkom siječnja 1943. godine. Nije poznato do kada ju je vršio.

${ }^{28}$ Prisustvovalo je šest osoba. Potpisi su nečitljivi ne samo zbog rukopisa, već i zbog vlage koja ih je razlila po papiru.

29 Tekst se nalazi u Dužnostniku, br. 10, 1942., 621-623.
} 
c. za St. mladež

načelo. Pregledati sveske za domaće zadaće i dati ocijene za mj. [nečitljivo] [listopad?]

Umijeće: svaki pripadnik sam ponoviti dosad učene pjesme. Vojna prednaobrazba ocijeniti dosad stečeno dojmom, sa sastanaka.

Tijelovježba: kao Vojna prednaob.

Igre: također.

I dati ocjene iz stege, uljudnosti, točnosti itd.

Pošto Zap. St. Ml. nije bio prisutan, toće se od njega tražiti pismeno opravdanje.

III. Opomena zap. St. ml. Pavlu Višnjovskom

Da se pošalje opomena zap. St. ml. za neizvršenje dužnosti.

IV. Nabavka inventara.

Za današnje prilike nam je nemoguće kupiti inventar III. točke sa poslednje sjednice, radi toga što taj inventar mnogo košta te će mo to odgoditi za prilike kada će mo biti u mogućnosti nabaviti tolik novac, za taj inventar.

V. Osnivanje štednog kola dužnostnika M. Ust. ml.

Da se osnuje štedno kolo sa mjesečno od $100 \mathrm{kn}$ (sto kuna) ili pok. od $50 \mathrm{kn}$ (pedeset) po mogućnosti. Cilj štednog kola je da se osnuje knjižnica, da se nabave kape, pripadnicima koji su siromašnijeg stanja.

VI. Odabiranje štediše.

Pošto se nismo svi saglasili sa time, jer nisu svi na okupu odabiranje se odgađa za slijedeću sjednicu.

VII. Slijedeća sjednica.

Slijedeća sjednica se održaje 31. I. 43g. Opominju se svi dužnosnici da se strogo pridržavaju ovoga zapisnika, jer tko se ogrieši o ovaj zapisnik bit će ka- 
žnjen sa $50 \mathrm{kn}$. a koji novac ide u fond štednog kola.

Eventualije.

Sijednica je završena u $19.30^{\mathrm{h}}$

Za Poglavnika i Dom spremni!

Prisustvovali:

$[\ldots]^{30}$

M. Pletikapić

Zapisnik sa sijednice održane dne 31. I. 1943.

Sijednicu je otvorio brat tabornik sa slijedećim redom $\mathrm{u} 17^{\mathrm{h}}$

I. Čitanje zapisnika sa prošle sjednice

II. Podatci o pripadnicima.

Zapisnik je primljen.

Svaki zap. dobnih skupina da preda u najkraćem roku taboru slijedeće podatke:

I. obujmost grudi

II. visina

III. zdravlje

IV. lični opis

III. Pisanje mj. izvještaja.

IV. a) Održavanje sastanaka.

Svaki zap. će napisani izvještaj pročitati na sijednici.

Plan rada za Junak sa prošle sijednice je još na snazi, iz razloga što je logornica posjetila ž. ml. i imala sastanak sa ž. ml. te je sastanak Junaka odgođen za 2. II. $43 \mathrm{~g}$.

b) za Uzdanicu

\footnotetext{
${ }^{30}$ Prisustvovale su četiri osobe. Čitljiv je samo potpis Miroslava Pletikapića.
} 
c.) St. Mladež

dne: 7. II. 43g. sa slijedećim redom. prorada I. Ust. načela ispitivanja sa prošlih sastanaka sa ocijenama.

Igra: boj pietlova. pjesma Ust. koračnice, i Poglavnikovo kolo.

Ustaška načela. 5 Ust. načelo pjevanje koračnice „podigla se prašina“

IV. Pismeno opravdanje od zap. St. ml.

dne: 27. I. 43g. je zap. brat Pavao Višnjevski podneo pismeno opravdanje za nedolazak na sijednicu dne: 20. I. 43g.

Eventualije:

Sijednica je završena u $18.20^{\mathrm{h}}$

Za Poglavnika i Dom spremni!

Prisustvovali:

$[\ldots]^{31}$

Vjekoslav Koren ${ }^{32}$

M. Pletikapić

J. Đenđinović

Bunić Petar

Zapisnik sa sjednice održane: 3. II. 1943.

koja je održana u zajednici s Ž.U.M.

Sjednica je počela u $5 \mathrm{~h} 30 \mathrm{~m}$

I. Sastanak u čast Dr Milana Šuflaja.

Ž. Ust. Ml. daje tri recitacije, i predavanje o Milanu Šuflaju. M. Ust. Ml. daje samo tri recitacije.

\footnotetext{
${ }_{31}$ Prisustvovalo pet osoba.

32 Taborski zapovjednik Ustaške uzdanice. Na toj dužnosti naslijedio je Miroslava Pletikapića. Nije poznato do kada je tu dužnost vršio.
} 
II. Vrieme sastanka.

Sastanak će se održati dne 18.II.43g. u $16.30^{\mathrm{h}}$.

III. Za đake koji zakasne.

Ako vlak kasni, đaci koji ide u školu, dobiju opravdanje.

IV. Probe.

Proba će se održati 14.II.43g. po podne.

V. Eventualije.

Sijednica završena u $18^{\mathrm{h}}$.

Prisustvovali:

Tabornica: Jela Šičara

Zapovjednica U.J. i S.M. Blanka Brezinščak ${ }^{33}$

Zapovjednica U.U. Margita Behan ${ }^{34}$

$[\ldots]^{35}$

Zapisnik sa sijednice održane dne: 2.II.43g. koja je održana u zajednici s Ž.U. st. ml.

I. Pokladna priredba

Sijednica je počela u $5.20^{\mathrm{h}}$

U slučaju da nedobijemo dozvolu za noćnu pripredbu, ista će se održati poslije podne u $16^{\text {h }}$.

II. Slijedored

\footnotetext{
${ }_{33}$ Blanka Brezinščak na mjestu taborske zapovjednice Ustaških Junakinja naslijedila je Ivanu Burger. Ivanu Burger na dužnosti taborske zapovjednice Ustaških Junakinja ponovno nalazimo u travnju 1944. (Dužnostnik, 1944., br.4, 53). Iz broja spisa imenovanja 24648-XXI6355/43. jasno je da je imenovana negdje krajem 1943. godine. Što se tiče Blankine druge dužnosti, taborske zapovjednice Ustaške Starčevićeve mladeži, Zlata Radauš je imenovana zapovjednicom od 15. X. 1941. pa do 22. X. 1943. godine (Dužnostnik, 1944., br.1-3, 25). Negdje unutar toga razdoblja tu dužnost je preuzela Blanka Brezinščak.

${ }^{34}$ I zapovjednica Ustaške uzdanice tabora Vukovar unosi pomutnju u lanac imenovanih dužnosnica na tu dužnost. Naime, Ljubica Čorluk je tu dužnost vršila od 15. X. 1941. do 22. X. 1943. (Dužnostnik, 1944., br. 1-3, 25), što nam potvrđuje i Popis dužnostnika. Očito je i Margarita Behan imenovana na tu dužnost u međuvremenu.

${ }^{35}$ Imena četvorice dužnosnika muške mladeži nečitljiva su.
} 
III. Podjela dužnosti.

Nastupaju na priredbi Z. St. ml. i m. St. Ml. u igrokazu „liječnik proti volji“. Ž. i muški Junak u igrokazu „Stričeva oporuka" i ž. Uzdanica u igrokazu „Lezvuče za prolječem“.

Sestra Blanka donijet će blokove iz Karlovca o nabaviti dvie kutije reisnegla. Brat Bošnjak slagati stolice. Uređenje pozornice braća Čobranović i Koren. Pribijanje sestra Tabornica i brat Slaven.

Na blagajni brat Mohorovičić i sestra Damjanović.

Razvozdnice sestre Tabornica brat Koren brat Višnjovski. Režija komada brat Čobranović. Garderoba svako za sebe.

IV. Opomena dužnostnicima.

V. Eventualije.

Da se traži pismeno opravdanje od: sestra Margite Behan Zap. U.U. i brata Pavla Višnjivskog radi nedolaska na sijednicu dne: 2.III.43g.

Sijednica završena oko $18^{\mathrm{h}}$

Za Poglavnika i Dom spremni!

Prisustvovali:

Tabornica: Jela Šićara

Zap. U. Jun. i Star. M. Blanka Brezinščak

Zap. Ust. Uzd. Vjekoslav Koren

Zap. Ust. Junaka M. Pletikapić

Tabornik $^{36}$

Zapisnik sa sijednice održane dne 17.II.43g.

${ }^{36}$ Bez potpisa. 
Sijednicu je otvorio brat tabornik

u $18^{\mathrm{h}}$ sa slijedećim redom.

I. Čitanje zapisnika sa prošle sijednice:

Zapisnik je primljen.

II. Određivanje rada za sastanke.

a) Starčevićeva mladež

I. Sastanak: Epopeja Staljingrada

II. Čitanje iz Crne legije ${ }^{37}$

III. Čitanje iz knjige Poglavnik o boljševizmu. ${ }^{38}$

IV. Ustaške vrline ${ }^{39}$

b) Ust. Junak

c) Igre Uzdanice

Petoro braćo za četiri sastanka.

I. boj pietlova. vježbe oponašanje i slijepac traži palicu.

II. hvatanje, učenje pjesmica stupanje uz pjesmu

III. ispitivanje, davanje novih pjesmica, vježbe medicinkom

IV. Čitanje štiva iz Uzdanice vježbe oponašanja, stupanje uz pjesmu.

Sastanci će se održavati dne:

18-III-43g. od 4-5-6-7 ${ }^{\mathrm{h}}$.

22-III-43g. od 9-10-12 .

25-III-43g. od 4-5-6-7 .

28-III-43g. od 9-10-12 .

Sjednica završena u $19^{\mathrm{h}}$.

Za Poglavnika u Dom spremni!

Prisustvovali:

${ }^{37}$ Radi se o knjizi novinskih reportaža: Ivo Balentović, Crna legija - odredi nepobjedive mladosti (Zagreb, 1942).

38 Julije Makanec, Poglavnik o boljševizmu (Zagreb, 1942).

39 Julije Makanec, Ustaške vrline (Zagreb, 1942). 
tabornik: $[\ldots]^{40}$

Zap. St. ml. Pavao Višnjovski

Zap. Ust. Junaka $[\ldots]^{41}$

Zap. Ust. Uzd. Vjekoslav Koren

Zapisnik sa sijednice održane dne 17-III-1943. sa ženskom mladeži

Sijednicu otvorio tabornik u $19^{\mathrm{h}}$ sa ovim redom

I. Prihod sa priredbe

II. Izdato

I. mj. prodano 91 karata po $50 \mathrm{kn}$

II. mj. -II- 74 -II- -II- $30 \mathrm{kn}$

Stojanje -II- 8 -II- -II- $15 \mathrm{kn}$

dobrovoljni prilog $170 \mathrm{kn}$.

sa prošl. dana Starčevića

$932 \mathrm{kn}$.

ukupno $7.992 \mathrm{kn}$.

$100 \mathrm{kn}$ za dvoranu

$600 \mathrm{kn}$ za karte

$700 \mathrm{kn}$ za skela [nejasno] ${ }^{42}$

$200 \mathrm{kn}$ za prevozninu

plakate $150 \mathrm{kn}$.

ukupno $1750 \mathrm{kn}$

čistog prihoda $6242 \mathrm{kn}$.

od toga $3121 \mathrm{kn}$ dobije S. ml.

a $3121 \mathrm{kn}$ dobije $\mathrm{m}$. uib. [nejasno]

III. Nabavke

Da se naruči cjelokupna djela Dostojevskog i da se zatraži katalog od St. Kuglia

\footnotetext{
${ }^{40}$ Potpis nečitak.

${ }^{41}$ Nedostaje potpis.

${ }^{42}$ Vjerojatno se odnosi na skelu kao prijevozno sredstvo preko rijeke, najvjerojatnije za prijevoz preko Dunava.
} 
IV. Priredba 10-IV-1943g.

\author{
stol za ping-pong ${ }^{43}$ \\ Cjelokupni rashod za dole navede- \\ ne stvari izdat će se iz prihoda sa \\ priredaba. \\ Da se nabavi jedan Baringov riječnik 5 \\ izdanja $115 \mathrm{kn}$.
}

Muški i ženski zbor će pjev. 'Lijepa naša' Puška puca 'Glasna jasna' 'Strgnusmo lance' 'Zviezde iz kamena' Ženske će plesati kolo:

'zeleni se gora sva'

'sam se ...'

za muškarce će se naknadno odrediti.

V. Eventualije

Sijednica završena u $19.35^{\mathrm{h}}$.

Prisustvovali:

tabornica: Jela Šičara

Zap. Ust. St. ml. Blanka Brežinšćak ${ }^{44}$

Zap. Ust. Uzd. Margita Belan

tabornik: $[\ldots]^{45}$

Zap. Ust. St. ml. Pavao Višnijevski

Zap. Ust. Junaka M. Pletikapić

Zap. Ust. Uzdanice Vjekoslav Koren

${ }^{43}$ U prvom zapisniku donijeta je odluka da se 1. VIII. 1942. naruči stol za stolni tenis. Izgleda da još niti sredinom ožujka 1943. godine nije nabavljen.

${ }^{44}$ Budući da je navedene kao zapovjednica Starčevićeve mladeži, očito više nije taborska zapovjednica i Ustaških Junakinja, kako je to bilo navedeno u Zapisniku sa sastanka održanog 2.II.1943.

${ }^{45}$ U tjedniku Ustaška mladež postoji izvještaj s gostovanja tabora Ustaške mladeži Vukovar u Ilok. Ustašku mladež na tom putu, na koji su krenuli 13. ožujka 1943. vodili su logornik Ante Đurković, tabornik Mijo Kuhner te vlč. Silvestar Zubić. Osim predavanja logornika Đurkovića, održan je i igrokaz Zub za zub. Usp. Gostovanje u Iloku, Ustaška mladež, br. 8, 1. V. 1943., 12. Dakle, tada je tabornik Ustaške mladeži grada Vukovara Mijo Kuhner. 
Zapisnik sa sijednice održane 7-IV-1943g. sa ženskom mladeži

Tabornik otvara sijednicu u $16^{\mathrm{h}}$.

I. Priredba 10-IV-43g.

II. Nabavka kape pripadnicima.

Priredba će se održati na nogometnom igralištu u koliko vreme posluži.

III. Podjela rada

Kape će da se isplate iz štednog kola, a pripadnici će naknadno otplačivat.

Rad oko ženskih vježbi će voditi sestra Belan i Brezinščak.

Vježbe muškaraca radi brat Ćobanović. Vjekoslav Koren M. Pletikapić Ćobanović će voditi rad oko pripreme za vježbu, kao i Višnjovski.

Na blagajni brat Mohoričić.

IV. Podjela kapa

Osam za uzdanicu i Junak ženski i osam za jedne i druge muškarce.

V. Eventualije:

Sastanak završen u $17^{\mathrm{h}}$.

Za Poglavnika i Dom spremni!

Prisustvovali:

tabornica J. Šičara

Zap. Us. J. i St. ml. Blanka Brezinščak

Zap. Ust. Uzdanice Margita Belan

tabornik $[\ldots]^{46}$

Zap. Ust. Junaka M. Pletikapić

Zap. Ust. Uzdanice V. Koren

${ }^{46}$ Nečitljivo. 


\section{Summary \\ PROTOCOLS FROM THE MEETINGS OF THE VUKOVAR USTASHA YOUTH CAMP}

(July 1942 - April 1943)

The protocols from the meetings of the Vukovar Ustasha Youth Camp are significant historical sources giving an insight into the activities and operations of the local organization of the Ustasha Youth within the Independent State of Croatia. Even though this involves a rather short period of time, a few months only, it is possible to reconstruct the dynamics of the implementation of directives from the centre (Zagreb Ustasha Youth Command) as well as of the superior Headquarters of the Ustasha Youth Vuk I.

The protocols present the scope of work and the problems the local organization of the Vukovar Ustasha Youth Camp had to face in its activities. The publishing of such sources allows us to draw comparisons between the successes as presented in propaganda, which can be read about in numerous newspapers of the Ustasha Youth, and the reality that presented obstacles to local officials of the Ustasha Youth.

It is fairly certain that protocols of local organizations of the Ustasha Youth are kept in other archives as well; hence, this is a suggestion for others to publish these protocols and make them available to the interested scholarly community.

Keywords: Independent State of Croatia (NDH), Vukovar, Ustasha Youth organization, camp

(Translated by Mica Orban Kljajić)

\section{Kontakt autora:}

Dr. sc. Petar Macut

e-mail: petarma@net.hr 